\title{
Numerical Modal Analyses of Beam-Supported Plates with Varying Thicknesses
}

\author{
Adil Yucel \\ Department of Mechanical Engineering, Istanbul Technical University, Gumussuyu, Istanbul, Turkey. \\ E-mail: adil.yucel@itu.edu.tr
}

(Received 15 July 2021;; accepted 30 August 2021)

In this study, numerical modal analyses are conducted on steel plates supported with various numbers of transverse beams. Natural frequency and mode shapes are obtained for each model. The same analyses are also repeated for plates with various thicknesses. Finally, the correlation between the number of supporting beams and natural frequencies is examined. The change in natural frequencies with respect to plate thickness is emphasized. In addition, general surface regression formulas of flexural natural frequencies with respect to the number of supporting beams and plate thicknesses are obtained.

\section{INTRODUCTION}

Steel plates can be reinforced or supported with various numbers of transverse beams. The number of transverse beams and the thickness of plates can change the natural frequencies and mode shapes of these structures. The goal of this study is to present a relationship between the change in the number of transverse beams and natural frequencies. This study also emphasizes the effect of plate thickness. A detailed literature review is conducted concerning beam-reinforced and beam-supported plates.

Mróz and Rozvany derived the optimal support location as an elastic design for a given compliance and a plastic design for a specific safety factor of plastic collapse. ${ }^{1}$ After, they formulated the optimal design problem, including the cost of support based on position and considered both rigid and flexible or yielding supports.

Jang et al. used a sprung structure model to develop a fast gradient-based optimization approach in order to find the optimal support locations of beam and plate structures under selfweight. ${ }^{2}$ They formulated the problem of support locations with continuous design variables to use this gradient-based algorithm. They assumed that the beam or plate structure was supported by a set of distributed springs that are attached to all nodes of a discretized model. Spring stiffness was considered a continuous variable, with limited stiffness values for the springs during unsupported and supported states. The elastically supported structures show significantly different structural behaviors from other structures. Therefore, choosing an objective function that meets the design goals and ensuring convergence to distinct states without some intermediate states are not easy to do. An extensive research was carried out to address this issue and to suggest an appropriate objective function. Also, an optimization formulation using this objective function is given, and this formulation is checked for validity and usefulness with some numerical problems.

Sapountzakis proposed an improved model to analyze plates stiffened by parallel beams, including creep and shrinkage ef- fects. $^{3}$ The model allows static analysis of reinforced concrete plates stiffened by arbitrarily placed parallel reinforced concrete or steel beams with deformable connections. It also considers the effect of creep and shrinkage effects relative to the time of casting and the time of loading. Accordingly, the stiffening beams are isolated from the plate by sections in the lower outer surface, suggesting that the plate and the beams can slip in all directions of the connection without separating, even under arising tractions at the fictitious interfaces. These tractions are integrated according to each half of the interface width, resulting in two interface lines. The loading of the beams and the additional loading of the plate are defined along these two lines. Continuity conditions are applied in all directions of the interfaces to establish the unknown distribution of the plates and beams, considering their relation with interface slip through shear connector stiffness. Using two interface lines for each beam allows for the distribution of the interface transverse shear forces nonuniformly and consideration of the nonuniform torsional response of the beams, which yields a better response definition of the plate-beam system. The plate and the beams are analyzed on their deformed shape, considering second-order effects. Six order boundary value problems are formulated and solved using the analog equation method (AEM). The nonlinearly coupled plate and beam problems are solved using iterative numerical methods. This model better defines the response of the plate-beam system and allows for the evaluation of the shear forces at the interfaces in both directions. This has particular importance in the design of prefabricated ribbed plates. There seems to be considerable discrepancies between the lateral deflections of plate-beam systems and other models since these tend to neglect plane and axial forces and deformations. It also offers numerical examples with great practical interest.

Most results on the inverse problem of determining loads on elastic beams or plates under transverse vibration refer to a single beam or single plate. Kawano and Morassi determined the sources in multispan systems by connecting either two Euler-Bernoulli elastic beams or two rectangular Kirchhoff-Love 
elastic plates. ${ }^{4}$ They assumed the structural material to be homogeneous and isotropic. Here, the transverse load is given as $\mathrm{g}(\mathrm{t}) \mathrm{f}(\mathrm{x})$, where $\mathrm{g}(\mathrm{t})$ is a known function of time and $\mathrm{f}(\mathrm{x})$ is the unknown term based on the position variable $\mathrm{x}$. Under some given assumptions, a uniqueness result for $\mathrm{f}(\mathrm{x})$ is proven for dynamic response observations at interior points in a smalltime interval. The authors also included a numerical implementation of the method to demonstrate the possible application of the results for the practical identification of the source term.

He and Feng conducted a vibration analysis on an elastically connected multiple beam (ECMB) system under a moving oscillator and applied a finite sine-Fourier transform to the dynamic partial differential equations of the ECMB according to space coordinates. ${ }^{5}$ They used a numerical integration to solve the equations and derived the expression for vibration analysis of the ECMB based on a finite sine-Fourier inverse transform. The developed method and the ANSYS numerical method allowed the vibration analysis of a four-layer beam system under a moving oscillator at different speeds. The findings were in good coherence with the ANSYS numerical calculation results, with less than $2 \%$ calculation differences between the two, verifying the correctness of the developed method. This method is also applied to a beam-rail system on a railway line in China, where the effect of the train speed and interlayer stiffness on the vibration of the beam-rail system was examined. The maximum dynamic deflection of the rail under the train load was found always to be near the midspan, while that of the track plate, base plate, and bridge only occurred once the train traveled through the midspan. It was shown that the interlayer stiffness had a high effect on the vibration of the rail and the track plate and only a slight influence on the vibration of the base plate and the bridge.

Takabatake and Nagareda conducted a simplified analysis of elastic plates with edge beams, presenting a simplified analytical method for rectangular plates with edge beams under the validity of the Kirchhoff-Love hypotheses. ${ }^{6}$ The accuracy of the Galerkin method depends on the shape functions. Still, the suitable shape functions that meet the boundary conditions of plates with edge beams are not easy to determine. Thus, the plate supported with edge beams is replaced with a plate supported with edges that are elastically restrained against translation and rotation. The shape functions in the current plate use the shape functions of beams supported with equivalent translational and torsional stiffness. Using the Galerkin method, one can propose approximate but accurate solutions for static and dynamic problems of rectangular plates with edge beams. The numerical findings obtained from this theory for isotropic plates with edge beams are in accordance with those obtained from the finite element method (FEM) using FEM code MSC/NASTRAN.

Sapountzakis and Katsikadelis conducted a dynamic analysis of elastic plates reinforced with beams of a doubly symmetrical cross section and presented a solution to the dynamic problem. ${ }^{7}$ Their model associates the rise in plane forces and deformations of the plate and the axial forces and the deformations of the beam with the combined response of the system.
In the analysis, the beams are isolated from the plate by sections parallel to the lower outer surface. This analysis is based on establishing a flexibility matrix according to a set of nodal mass points using AEM for the static plate problem. A lumped mass matrix is constructed from the tributary mass areas to the nodal mass points. The model considers both free and forced transverse vibrations, yielding numerical examples with great practical interest. The discrepancy in the eigenfrequencies obtained by this analysis better matches the response of the platebeam system, while the corresponding eigenfrequencies ignore the in plane forces and deformations.

Seo et al. developed a power flow analysis method to estimate the vibrational responses of reinforced beam-plate coupled structures at medium to high frequencies. ${ }^{8}$ This method was applied to simply supported rectangular plates reinforced with multiparallel beams using the power flow coupling relationships at the beam-plate junctions and the zero intensity conditions at the plate edges. Numerical simulations were used to compare the power flow energy density and intensity fields between two plates with a single beam and eight beams and classical displacement solutions. As a result, the fields were in agreement with global decay and attenuation patterns of energy density.

Rook and Singh defined a computational strategy based on component mobility and modal synthesis approaches to calculate structural power flow through multidimensional connections. ${ }^{9}$ They presented sample case: a beam (shaft), ball bearings, and an elastic machinery casing plate, highlighting the calculation of structural intensity. They outlined a new presynthetic algorithm to determine effective stiffness for ball bearings, considering the compliance of the neighboring structure. The finite element method was used to make the computations easier and to generate structural intensity results in postsynthesis mode.

Chiba and Yoshida presented a free vibration analysis by the Rayleigh-Ritz method for a rectangular plate-beam coupled system. ${ }^{10}$ Their system consisted of a cantilever rectangular plate and either a pair of beams or a single beam connected to the free end side furthest from the support. They provided natural frequencies and vibration modes for various system configurations (length ratio between the plate and the beam, aspect ratio of the plate, and distance between beams). An experiment was performed with $0.5 \mathrm{~mm}$-thick polystyrene test plates to confirm the validity of the analysis and the findings observed were in good coherence.

$\mathrm{Hu}$ and Hartley performed an elastic analysis on thin plates with beam supports and presented the findings for two model types: 1) a boundary condition where the plate and the edge beam are connected continuously; and, 2) an attached beam element where the connection is not fully displacementcompatible. ${ }^{11}$ The authors provided some overall guidelines for the numerical analysis of plates with attached beams. For example, the discontinuation of a beam support along a plate edge leads to a special singular condition. The validity of a mathematical model under this condition would pique the interest of structural designers. They based the numerical modeling of thin plates on the direct boundary element method, fully 
defining the procedures used in attaching edge beams. They also gave numerical results for square plates in comparison with established cases. These functional computations have been used to solve problems involving thin plates of general plan shape and transverse loading.

Galbrun examined the modeling of vibration transmission through plate/beam structures that are typical in lightweight buildings. ${ }^{12}$ They performed key experiments on simple structures to determine the applicability and limitations of basic theories, including a single plate connected to a beam along its center, two parallel plates attached to a beam along their center (opposite or offset plates), and four plates connected to a beam along their edges. The analysis is centered around the applicability of modeling a beam as a one-dimensional element in point-connected systems. Statistical energy analysis (SEA) formed the framework for all predictions, while the theories were independent of SEA. The findings indicated that simple point models are only applicable to single plate, beam systems, and parallel opposite plates connected to a beam along their center, albeit solely at low to mid frequencies (below $2 \mathrm{kHz}$ ). They also examined transmission between two parallel plates connected to a beam with closely spaced screws. Accordingly, the rigid and pinned line predictions could provide some limits for transmission between panels on the same side of a wall.

Shu and Du offered a new method to implement clamped and simply supported boundary conditions in the free vibration analysis of beams and plates using generalized differential quadrature (GDQ) ${ }^{13}$ Their approach replaced the boundary conditions with the governing equations, called the satisfying the boundary conditions in the general solution (SBCGS) approach. Accordingly, SBCGE overcomes the limitations of previous approaches when treating boundary conditions. They compared SBCGE with the modifying weighting coefficient matrices (MWCM) method, applying both methods to the vibration analysis of beams and plates under combinations of simply supported and clamped boundary conditions.

Mitra et al. presented a large-amplitude free vibration analysis of uniaxially single stiffened rectangular plates subjected to transverse loading under simply supported boundary conditions. ${ }^{14}$ Their mathematical formulation was based on the energy principle and geometric nonlinearity was explained by considering nonlinear strain-displacement relations. The static problem was solved by an iterative scheme and the dynamic problem by taking the static displacement field as an initial assumption. They investigated the effect of stiffener position, plate aspect ratio, and stiffener-to-plate thickness ratio on a large amplitude dynamic behavior. Furthermore, the dynamic behavior was supplied with backbone curves in a dimensionless frequency-amplitude plane.

Mackerle listed references to papers on the finite element vibration analysis of beams, plates, and shells between 1994 and 1998, including 361 citations. ${ }^{15}$ This list also contained the vibration analyses of composite materials and structural elements with cracks/contacts.

Sapountzakis and Katsikadelis presented a solution to the problem of plates reinforced with beams. ${ }^{16}$ Their model considered an increase in plane forces and deformations of the plate and the axial forces and deformations of the beam due to the combined response of the system. In the analysis, the beams are isolated from the plate by sections parallel to the lower outer surface. Forces producing lateral deflection and in plane deformation to the plate and lateral deflection and axial deformation to the beam are established using continuity conditions at the interface. The nonlinearly coupled plate and beam problems are solved using AEM. This model better defines the response of the plate-beam system, allowing to assess the shear forces at the interface, which is key for the design of composite or prefabricated ribbed plates. The arising deflections are significantly smaller than those obtained in other models.

Aydoğdu and Taşkın investigated the free vibration of a simply supported functionally graded (FG) beam. ${ }^{17}$ The Young modulus of the beam changed in the thickness direction based on power law and exponential law. Hamilton's principle is used to find the governing equations and the Navier-type solution method is used to obtain frequencies. The analysis utilizes different higher-order shear deformation theories and classical beam theories, yielding outcomes for different material properties and slenderness ratios.

Sinha et al. focused on numerical and experimental studies on the free vibration of woven glass fiber laminated composite stiffened plates. ${ }^{18}$ The authors tested thirty-four stiffened plates with different parameters fabricated from woven glass fiber and binder (epoxy and hardener) in an FFT analyzer to obtain their natural frequencies. They used a finite element model for the validation of experimental findings. A comparison of the experimental and numerical results indicates agreement, highlighting significant effects of parameters on fundamental frequency.

Mikkola and Shabana investigated a nonincremental solution for the finite rotation and large deformation analysis of plates. ${ }^{19}$ Their method is based on absolute nodal coordinate formulation and yields plate elements that can exactly represent rigid body motion. The method makes use of the continuity conditions on all the displacement gradients, avoiding nonsmoothness of the plate mid-surface at the nodal points. Different from other finite element formulations that give highly nonlinear inertial forces for 3D elements, this method yields a constant mass matrix, equating the centrifugal and Coriolis inertia forces to zero. Besides, it has less reliance on some of the assumptions of the classical and Mindlin plate models that automatically meet objectivity requirements. It obtains a relatively simple expression for elastic forces using a general continuum mechanics approach. The study further discusses the generalization of this model to shell elements using two different plate elements: one that guarantees continuity of displacement gradients between nodal points and one that does not. Numerical results are given to show the use of the method in the large rotation and deformation analysis of plates and shells and are compared with those from existing incremental approaches. Accordingly, the solution obtained by this method meets the principle of work and energy. The findings are obtained using the explicit numerical integration method. The model promises some potential applications, such as high-speed metal forming, 
vehicle crashworthiness, rotor blades, and tires.

Sun and Wei presented a frequency domain formulation of the singular boundary method (SBM) to analyze thin elastic plates subjected to dynamic loads. ${ }^{20}$ SBM takes the fundamental solutions for the dynamic thin plate problem in the frequency domain as its base functions. The origin intensity factors (OIFs) are derived for the kernels of SBM to isolate singularities and to ensure that the source points comply with the collocation points. Along with SBM, the exponential window method (EWM) is applied for transient analysis to obtain time-domain outcomes. The authors conducted several examples under harmonic and transient loads and compared these with exact solutions and finite element solutions to show the efficacy and accuracy of their method.

Kukreti and Cheraghi presented a procedure to analyze stiffened plate systems (a plate supported by a network of steel girders). ${ }^{21}$ They considered two types of plate systems: 1) where the beams are parallel to the span (a ribbed plate system); and, 2) where the ribs and cross beams are perpendicular to the span (a grid plate system). The rigid connection of the beams to the plate is assumed, which is common in highway bridge decks and building-floor systems. The analysis is based on energy principles. They proposed a formulation of the deflection function for the plate, which helps calculate the moments in the plate due to general static loading. The findings are compared with the finite element method. In conclusion, the function could well represent plate behavior and was more efficient in terms of calculations.

In the study of Sobhani et al., the natural frequency responses of joined hemispherical-cylindrical-conical shells made of composite three-phase materials have been utilized in the framework of First-Order Shear Deformation Theory (FOSDT). ${ }^{22}$ The joined hemispherical-cylindrical-conical shells were assumed to be made of hybrid porous nanocomposite material with three phases including a matrix of epoxy, macroscale carbon fiber, and nanoscale 3D Graphene Foams (3GFs). To obtain the equivalent mechanical properties of the Hybrid Matrix (HM) including polymer epoxy and 3GFs, the well-known rule of the mixture was used.

Civalek and Avcar presented the free vibration and buckling analyses of functionally graded carbon nanotube-reinforced (FG-CNTR) laminated non-rectangular plates, i.e., quadrilateral and skew plates, using a four-noded straight-sided transformation method. ${ }^{23}$ Initially, the related equations of motion and buckling of quadrilateral plates were given, and subsequently, these equations were transformed from the irregular physical domain into a square computational domain using the geometric transformation formulation via a discrete singular convolution (DSC). The discretization of these equations was obtained via a two-different regularized kernel, i.e., regularized Shannon's delta (RSD) and Lagrange-delta sequence (LDS) kernels in conjunction with the discrete singular convolution numerical integration. The convergence and accuracy of the present DSC transformation were verified via existing literature results for different cases.

In the study of Hadji and Avcar, a free vibration analysis of the square sandwich plate with functionally graded (FG)

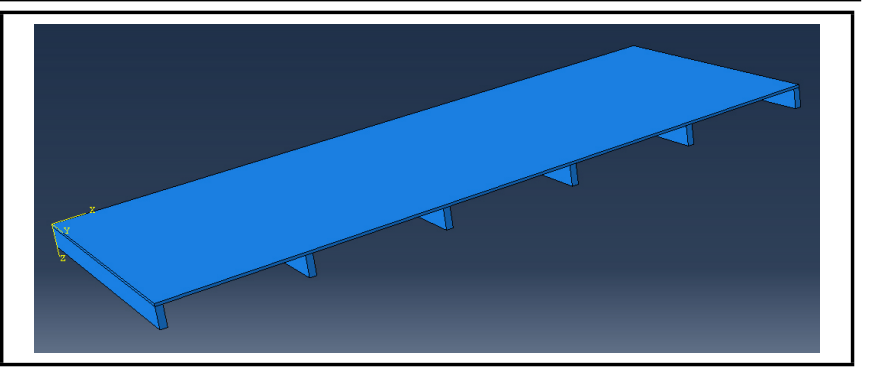

Figure 1. The 6-beam model with a plate thickness of $8 \mathrm{~mm}$.

porous face sheets and isotropic homogenous core was performed under various boundary conditions. ${ }^{24}$ For this purpose, the material properties of the sandwich plate were supposed to vary continuously through the thickness direction according to the volume fraction of constituents that were defined with the modified rule of the mixture including porosity volume fraction with four different types of porosity distribution over the cross-section.

In the work by AlSaid-Alwan and Avcar, an analytical solution of the free vibration of the beam composed of functionally graded materials (FGMs) was presented utilizing different beam theories. ${ }^{25}$ The comparison of the supposed beam theory for free vibration of functionally graded (FG) beam was examined. With this goal in mind, the Euler-Bernoulli, Rayleigh, Shear, and Timoshenko beam theories were employed. The functionally graded material properties were assumed to vary continuously through the thickness direction of the beam with respect to the volume fraction of constituents. The governing equations of the free vibration of the FG beams were derived in the frameworks of four beam theories. Analytically, the resulting equations were solved versus simply supported boundary conditions.. To verify the results, comparisons were carried out with the available results.

In the study of Zhang et al., the two-dimensional generalized finite integral transform (FIT) approach was extended for new accurate thermal buckling analysis of fully clamped orthotropic thin plates. ${ }^{26}$ The clamped-clamped beam functions, which can automatically satisfy boundary conditions of the plate and orthogonality as an integral kernel to construct generalized integral transform pairs, were adopted. Through performing the transformation, the governing thermal buckling equation can be directly changed into solving linear algebraic equations, which reduces the complexity of the encountered mathematical problems and provides a more efficient solution. The obtained analytical thermal buckling solutions, including critical temperatures and mode shapes, match well with the finite element method (FEM) results, which verifies the precision and validity of the employed approach.

\section{ANALYSES OF BEAM-SUPPORTED PLATE MODELS}

The number of transverse beams varied between 3 and 10 . Therefore, 8 different plate models for a certain plate thickness were constructed. The beams were equally spaced lengthwise over the plate, which is $2000 \mathrm{~mm}$ long, and the beams were $60 \times 20$ steel profiles. The model plate had a width of $800 \mathrm{~mm}$. 


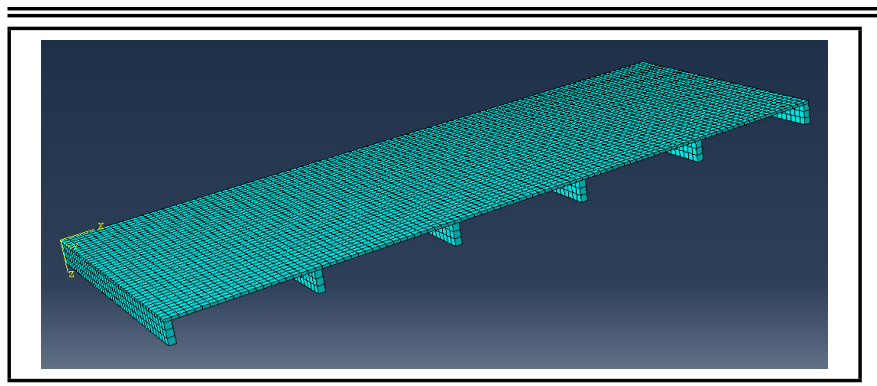

Figure 2. The finite element model of the 6-beam model with a plate thickness of $8 \mathrm{~mm}$.

Table 1. Natural frequencies of the sample model.

\begin{tabular}{|c|c|c|}
\hline Mode No & Natural Frequency & Mode Type \\
\hline \hline 1 & $30.12 \mathrm{~Hz}$ & First flexural mode \\
\hline 2 & $53.35 \mathrm{~Hz}$ & First torsional mode \\
\hline 3 & $83.44 \mathrm{~Hz}$ & Second flexural mode \\
\hline 4 & $91.57 \mathrm{~Hz}$ & Second torsional mode \\
\hline
\end{tabular}

The plate thicknesses varied between 2 and $16 \mathrm{~mm}$ (increasing by $2 \mathrm{~mm}$ ). Therefore, we had 8 plate thickness values for each system. Finally, 64 different models were constructed. The 6beam model with a plate thickness of $8 \mathrm{~mm}$ is shown in Fig. 1.

The beams were rigidly modeled, and rigid elements were applied. The plate element size is $20 \mathrm{~mm}$. The model was meshed using a structured hexahedral algorithm. The density, modulus of elasticity and Poisson ratio were $7850 \mathrm{~kg} / \mathrm{m}^{3}$, $200000 \mathrm{MPa}$ and 0.3 , respectively. The finite element model is shown in Fig. 2.

When we reviewed the analysis results of the 6-beam model with a plate thickness of $8 \mathrm{~mm}$, the first 4 natural frequencies are listed in Table 1. The mode shapes are also given in Figs. 36.

The same analysis procedures were applied to all 64 models. In the analyses, the eigenvalues were extracted in the range of $0-1200 \mathrm{~Hz}$. The modes shapes were also plotted for each model. The mode shapes repeatedly followed one flexural shape and one torsional shape. The mode shapes in which only the center span deforms are shown in Fig. 7.

Following the 64 numerical analyses, the results shown in Table 2 are obtained, which shows the first 3 in-plane flexural modes for the constructed models.

Figure 8 shows the relation of frequencies for the first 3 modes of the $8 \mathrm{~mm}$ thickness plate with respect to the number of beams. When this graphic for all plate thicknesses was plotted, the same behavior was observed between the frequencies and number of beams. The figure shows that there is a quadratic relationship between the frequencies and number of beams.

In Fig. 8, quadratic regressions were also performed to obtain the formulas for the first 3 flexural frequencies with respect to the number of supporting transverse beams. The regression functions for each plate thickness are listed in Table 3 .

Table 3 shows a relationship between the thickness depen-

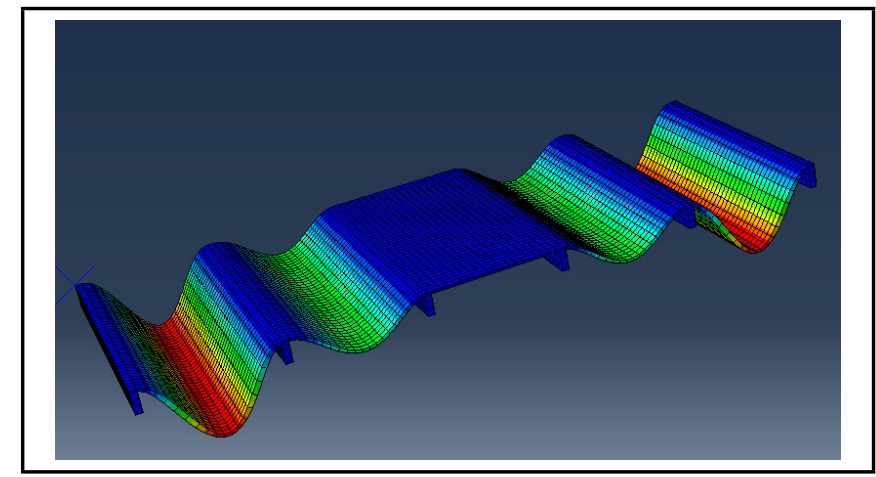

Figure 3. First flexural mode.

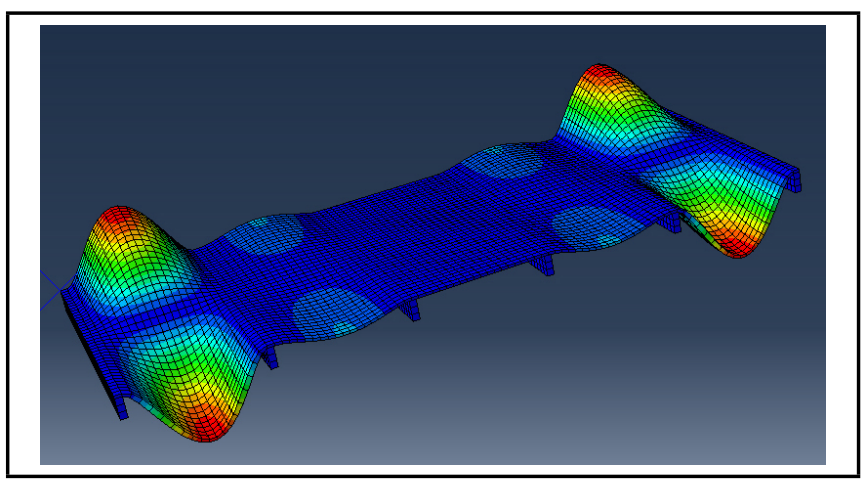

Figure 4. First torsional mode.

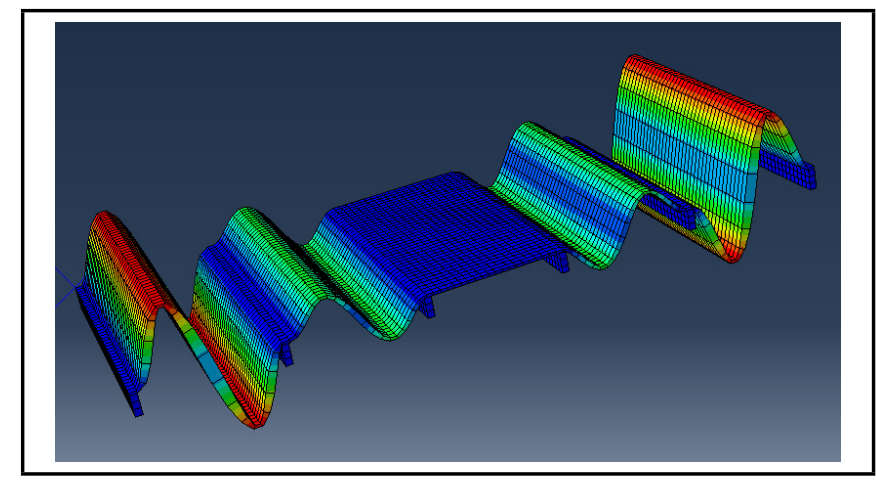

Figure 5. Second flexural mode.

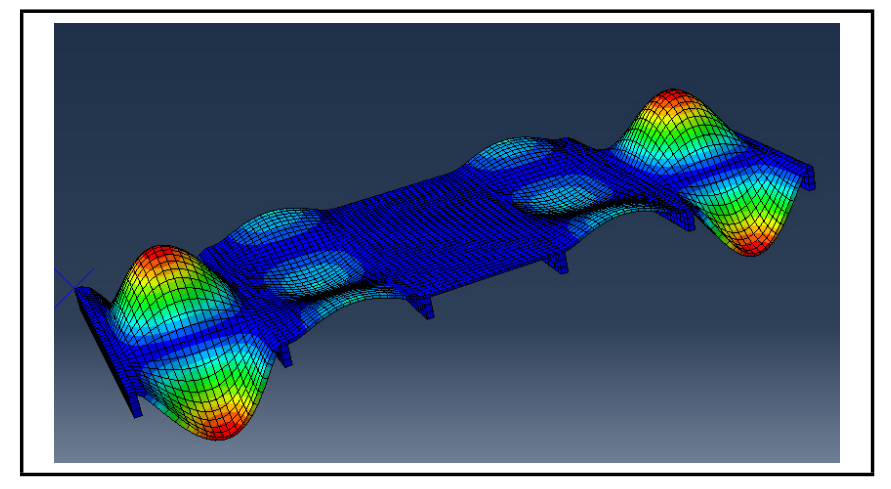

Figure 6. Second torsional mode 


\begin{tabular}{|c|c|c|c|c|c|c|c|c|c|}
\hline & & \multicolumn{8}{|c|}{ Number of Transverse Beams } \\
\hline & & 3 & 4 & 5 & 6 & 7 & 8 & 9 & 10 \\
\hline \multirow{8}{*}{ 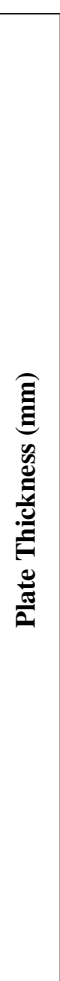 } & 2 & $\begin{array}{l}1.18 \mathrm{~Hz} \\
3.24 \mathrm{~Hz} \\
6.37 \mathrm{~Hz}\end{array}$ & $\begin{array}{c}2.65 \mathrm{~Hz} \\
7.32 \mathrm{~Hz} \\
14.39 \mathrm{~Hz}\end{array}$ & $\begin{array}{c}4.71 \mathrm{~Hz} \\
13.05 \mathrm{~Hz} \\
25.73 \mathrm{~Hz}\end{array}$ & $\begin{array}{c}7.54 \mathrm{~Hz} \\
20.92 \mathrm{~Hz} \\
41.39 \mathrm{~Hz}\end{array}$ & $\begin{array}{l}12.13 \mathrm{~Hz} \\
33.83 \mathrm{~Hz} \\
67.35 \mathrm{~Hz}\end{array}$ & $\begin{array}{l}16.20 \mathrm{~Hz} \\
45.35 \mathrm{~Hz} \\
90.82 \mathrm{~Hz}\end{array}$ & $\begin{array}{c}22.74 \mathrm{~Hz} \\
64.07 \mathrm{~Hz} \\
129.61 \mathrm{~Hz}\end{array}$ & $\begin{array}{c}27.62 \mathrm{~Hz} \\
78.19 \mathrm{~Hz} \\
159.47 \mathrm{~Hz}\end{array}$ \\
\hline & 4 & $\begin{array}{c}2.35 \mathrm{~Hz} \\
6.49 \mathrm{~Hz} \\
12.73 \mathrm{~Hz}\end{array}$ & $\begin{array}{c}5.29 \mathrm{~Hz} \\
14.63 \mathrm{~Hz} \\
28.76 \mathrm{~Hz}\end{array}$ & $\begin{array}{c}9.43 \mathrm{~Hz} \\
28.09 \mathrm{~Hz} \\
51.42 \mathrm{~Hz}\end{array}$ & $\begin{array}{l}15.70 \mathrm{~Hz} \\
41.82 \mathrm{~Hz} \\
82.69 \mathrm{~Hz}\end{array}$ & $\begin{array}{c}24.26 \mathrm{~Hz} \\
67.59 \mathrm{~Hz} \\
134.44 \mathrm{~Hz}\end{array}$ & $\begin{array}{c}32.39 \mathrm{~Hz} \\
90.59 \mathrm{~Hz} \\
181.15 \mathrm{~Hz}\end{array}$ & $\begin{array}{c}45.47 \mathrm{~Hz} \\
127.92 \mathrm{~Hz} \\
258.19 \mathrm{~Hz}\end{array}$ & $\begin{array}{c}55.20 \mathrm{~Hz} \\
156.06 \mathrm{~Hz} \\
317.33 \mathrm{~Hz}\end{array}$ \\
\hline & 6 & $\begin{array}{c}3.53 \mathrm{~Hz} \\
9.73 \mathrm{~Hz} \\
19.09 \mathrm{~Hz}\end{array}$ & $\begin{array}{c}7.94 \mathrm{~Hz} \\
21.93 \mathrm{~Hz} \\
43.11 \mathrm{~Hz}\end{array}$ & $\begin{array}{l}14.14 \mathrm{~Hz} \\
42.62 \mathrm{~Hz} \\
77.04 \mathrm{~Hz}\end{array}$ & $\begin{array}{c}22.60 \mathrm{~Hz} \\
62.66 \mathrm{~Hz} \\
123.80 \mathrm{~Hz}\end{array}$ & $\begin{array}{c}36.38 \mathrm{~Hz} \\
101.24 \mathrm{~Hz} \\
201.02 \mathrm{~Hz}\end{array}$ & $\begin{array}{c}48.57 \mathrm{~Hz} \\
135.62 \mathrm{~Hz} \\
270.56 \mathrm{~Hz}\end{array}$ & $\begin{array}{c}68.15 \mathrm{~Hz} \\
191.34 \mathrm{~Hz} \\
384.02 \mathrm{~Hz}\end{array}$ & $\begin{array}{c}82.73 \mathrm{~Hz} \\
233.28 \mathrm{~Hz} \\
472.04 \mathrm{~Hz}\end{array}$ \\
\hline & 8 & $\begin{array}{c}4.70 \mathrm{~Hz} \\
12.97 \mathrm{~Hz} \\
25.45 \mathrm{~Hz}\end{array}$ & $\begin{array}{l}10.59 \mathrm{~Hz} \\
29.23 \mathrm{~Hz} \\
57.43 \mathrm{~Hz}\end{array}$ & $\begin{array}{c}18.84 \mathrm{~Hz} \\
56.77 \mathrm{~Hz} \\
102.54 \mathrm{~Hz}\end{array}$ & $\begin{array}{c}30.12 \mathrm{~Hz} \\
83.44 \mathrm{~Hz} \\
164.63 \mathrm{~Hz}\end{array}$ & $\begin{array}{c}48.47 \mathrm{~Hz} \\
134.69 \mathrm{~Hz} \\
266.81 \mathrm{~Hz}\end{array}$ & $\begin{array}{c}64.71 \mathrm{~Hz} \\
180.32 \mathrm{~Hz} \\
358.51 \mathrm{~Hz}\end{array}$ & $\begin{array}{c}90.76 \mathrm{~Hz} \\
254.03 \mathrm{~Hz} \\
508.32 \mathrm{~Hz}\end{array}$ & $\begin{array}{l}110.13 \mathrm{~Hz} \\
309.54 \mathrm{~Hz} \\
621.74 \mathrm{~Hz}\end{array}$ \\
\hline & 10 & $\begin{array}{c}5.88 \mathrm{~Hz} \\
15.64 \mathrm{~Hz} \\
31.78 \mathrm{~Hz}\end{array}$ & $\begin{array}{l}13.23 \mathrm{~Hz} \\
36.51 \mathrm{~Hz} \\
71.69 \mathrm{~Hz}\end{array}$ & $\begin{array}{c}23.54 \mathrm{~Hz} \\
70.87 \mathrm{~Hz} \\
127.89 \mathrm{~Hz}\end{array}$ & $\begin{array}{c}37.63 \mathrm{~Hz} \\
104.11 \mathrm{~Hz} \\
205.03 \mathrm{~Hz}\end{array}$ & $\begin{array}{c}60.54 \mathrm{~Hz} \\
167.87 \mathrm{~Hz} \\
331.57 \mathrm{~Hz}\end{array}$ & $\begin{array}{c}80.79 \mathrm{~Hz} \\
224.63 \mathrm{~Hz} \\
444.64 \mathrm{~Hz}\end{array}$ & $\begin{array}{l}113.28 \mathrm{~Hz} \\
316.01 \mathrm{~Hz} \\
628.13 \mathrm{~Hz}\end{array}$ & $\begin{array}{l}137.33 \mathrm{~Hz} \\
384.40 \mathrm{~Hz} \\
765.03 \mathrm{~Hz}\end{array}$ \\
\hline & 12 & $\begin{array}{c}7.04 \mathrm{~Hz} \\
19.44 \mathrm{~Hz} \\
38.12 \mathrm{~Hz}\end{array}$ & $\begin{array}{l}15.87 \mathrm{~Hz} \\
43.78 \mathrm{~Hz} \\
85.88 \mathrm{~Hz}\end{array}$ & $\begin{array}{c}28.24 \mathrm{~Hz} \\
84.93 \mathrm{~Hz} \\
153.04 \mathrm{~Hz}\end{array}$ & $\begin{array}{c}45.12 \mathrm{~Hz} \\
124.61 \mathrm{~Hz} \\
245.04 \mathrm{~Hz}\end{array}$ & $\begin{array}{c}72.56 \mathrm{~Hz} \\
200.73 \mathrm{~Hz} \\
395.04 \mathrm{~Hz}\end{array}$ & $\begin{array}{c}96.80 \mathrm{~Hz} \\
268.40 \mathrm{~Hz} \\
528.57 \mathrm{~Hz}\end{array}$ & $\begin{array}{l}135.67 \mathrm{~Hz} \\
376.89 \mathrm{~Hz} \\
743.49 \mathrm{~Hz}\end{array}$ & $\begin{array}{l}164.28 \mathrm{~Hz} \\
457.45 \mathrm{~Hz} \\
900.05 \mathrm{~Hz}\end{array}$ \\
\hline & 14 & $\begin{array}{c}8.22 \mathrm{~Hz} \\
22.67 \mathrm{~Hz} \\
44.43 \mathrm{~Hz}\end{array}$ & $\begin{array}{l}18.50 \mathrm{~Hz} \\
51.00 \mathrm{~Hz} \\
99.98 \mathrm{~Hz}\end{array}$ & $\begin{array}{c}32.92 \mathrm{~Hz} \\
98.92 \mathrm{~Hz} \\
177.93 \mathrm{~Hz}\end{array}$ & $\begin{array}{c}52.38 \mathrm{~Hz} \\
145.13 \mathrm{~Hz} \\
284.43 \mathrm{~Hz}\end{array}$ & $\begin{array}{c}84.54 \mathrm{~Hz} \\
233.19 \mathrm{~Hz} \\
457.52 \mathrm{~Hz}\end{array}$ & $\begin{array}{l}112.71 \mathrm{~Hz} \\
311.05 \mathrm{~Hz} \\
609.92 \mathrm{~Hz}\end{array}$ & $\begin{array}{l}157.90 \mathrm{~Hz} \\
436.58 \mathrm{~Hz} \\
852.78 \mathrm{~Hz}\end{array}$ & $\begin{array}{c}190.99 \mathrm{~Hz} \\
528.37 \mathrm{~Hz} \\
1029.00 \mathrm{~Hz}\end{array}$ \\
\hline & 16 & $\begin{array}{c}9.39 \mathrm{~Hz} \\
25.89 \mathrm{~Hz} \\
50.73 \mathrm{~Hz}\end{array}$ & $\begin{array}{c}21.13 \mathrm{~Hz} \\
58.20 \mathrm{~Hz} \\
113.89 \mathrm{~Hz}\end{array}$ & $\begin{array}{c}37.57 \mathrm{~Hz} \\
112.83 \mathrm{~Hz} \\
202.54 \mathrm{~Hz}\end{array}$ & $\begin{array}{c}60.01 \mathrm{~Hz} \\
165.39 \mathrm{~Hz} \\
323.17 \mathrm{~Hz}\end{array}$ & $\begin{array}{c}96.46 \mathrm{~Hz} \\
265.19 \mathrm{~Hz} \\
518.24 \mathrm{~Hz}\end{array}$ & $\begin{array}{l}128.53 \mathrm{~Hz} \\
353.99 \mathrm{~Hz} \\
688.41 \mathrm{~Hz}\end{array}$ & $\begin{array}{l}179.95 \mathrm{~Hz} \\
494.93 \mathrm{~Hz} \\
958.34 \mathrm{~Hz}\end{array}$ & $\begin{array}{c}217.44 \mathrm{~Hz} \\
596.77 \mathrm{~Hz} \\
1149.30 \mathrm{~Hz}\end{array}$ \\
\hline
\end{tabular}

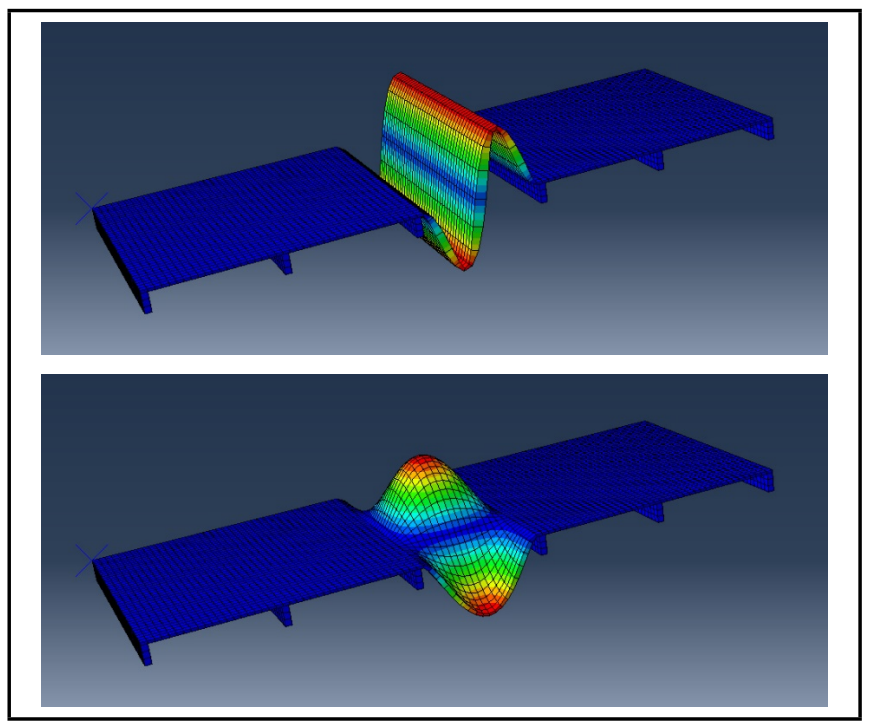

Figure 7. Center span flexural $(93.09 \mathrm{~Hz})$ and torsional $(97.34 \mathrm{~Hz})$ modes.

dent regression functions and plate thicknesses. Some general surface regressions over the frequency functions taking the plate thicknesses into consideration were conducted. In this way, the general frequency functions which take the number of supporting beams and plate thickness as inputs and calculations of the first 3 flexural natural frequencies were obtained. The general surface regression plots are shown in Figs. 9-11.

$$
\text { As we consider, }
$$

$\mathrm{n}=$ number of transverse supporting beams,

$\mathrm{t}=$ plate thickness $(\mathrm{mm})$, and

$\mathrm{f}=$ natural frequency $(\mathrm{Hz})$,

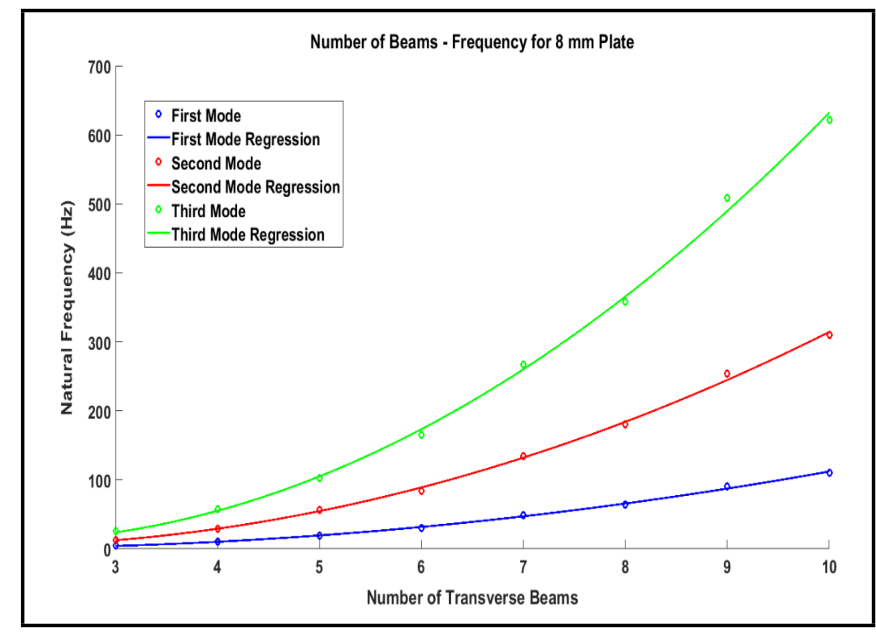

Figure 8. Frequency regressions with respect to number of beams.

the general natural frequency functions for the first 3 flexural modes are were obtained as follows.

$$
\begin{aligned}
\mathrm{f}_{1}(\mathrm{n}, \mathrm{t})= & (63.4)+(-22.33) \cdot \mathrm{n}+(-6.51) \cdot \mathrm{t}+ \\
& +(1.728) \cdot \mathrm{n}^{2}+(1.902) \cdot \mathrm{n} \cdot \mathrm{t} ; \\
\mathrm{f}_{2}(\mathrm{n}, \mathrm{t})= & (171.7)+(-61.02) \cdot \mathrm{n}+(-17.56) \cdot \mathrm{t}+ \\
& +(4.784) \cdot \mathrm{n}^{2}+(5.186) \cdot \mathrm{n} \cdot \mathrm{t} ; \\
\mathrm{f}_{3}(\mathrm{n}, \mathrm{t})= & (335.6)+(-120.7) \cdot \mathrm{n}+(-33.8) \cdot \mathrm{t}+ \\
& +(9.668) \cdot \mathrm{n}^{2}+(9.976) \cdot \mathrm{n} \cdot \mathrm{t} .
\end{aligned}
$$




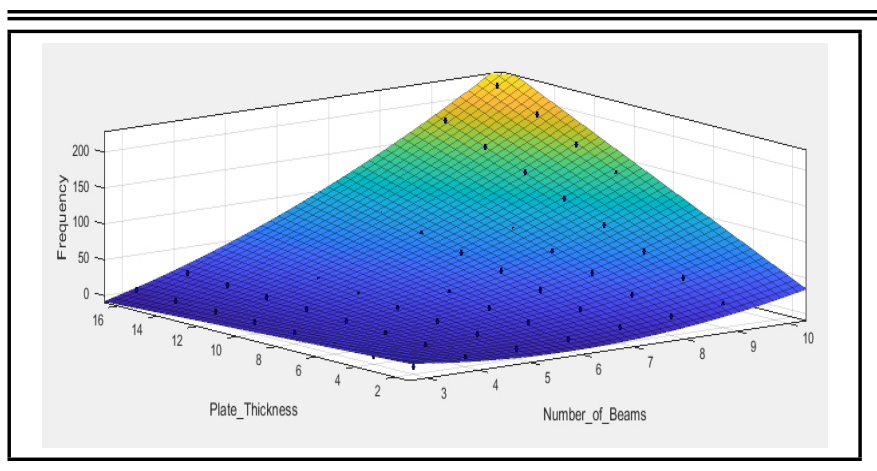

Figure 9. Surface regression plot for the first flexural mode.

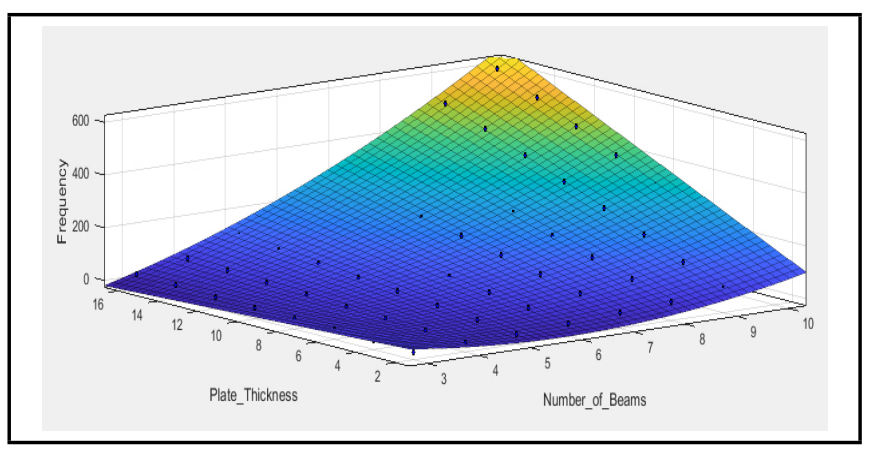

Figure 10. Surface regression plot for the second flexural mode.

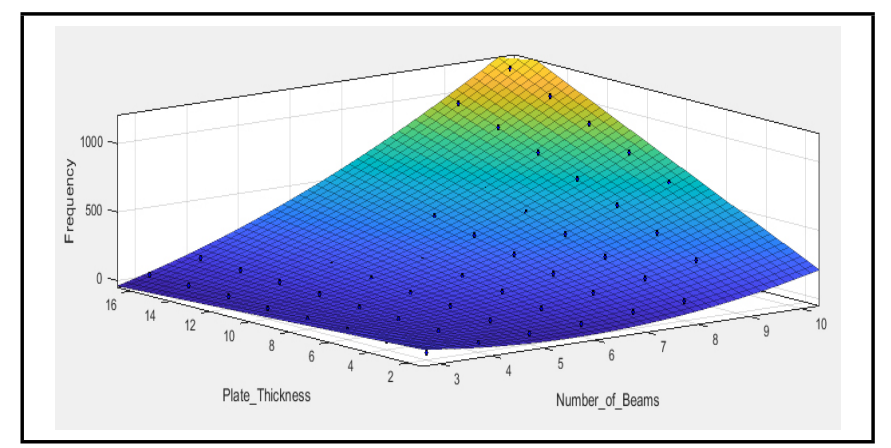

Figure 11. Surface regression plot for the third flexural mode.

\section{CONCLUSION}

Table 2, which gives the flexural natural frequencies of all models, clearly shows that the natural frequencies increased as the number of beams and plate thicknesses increased. The results show that there is a quadratic relationship between natural frequencies and the number of supporting transverse beams. This regression is clearly shown in Fig. 8. In addition, an examination of all the mode shapes showed that the mode shapes repeatedly follow one flexural shape and one torsional shape. The table of natural frequencies with respect to plate thicknesses showed that there was a relationship between the frequency functions and plate thicknesses. Some surface regressions over the frequency functions taking the plate thicknesses into consideration were conducted and overall general frequency functions were obtained with input variables being the number of supporting beams and plate thickness. The supporting transverse beams were equally spaced lengthwise over the plate, which is $2000 \mathrm{~mm}$ long, and the model plate had a width of $800 \mathrm{~mm}$. In future work, the model plate width and
Table 3. Regression functions.

\begin{tabular}{|c|c|c|}
\hline & & $\mathbf{n}=$ Number of Transverse Beams \\
\hline \multirow{8}{*}{ 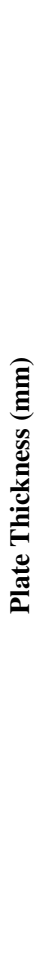 } & 2 & $\begin{array}{l}\mathrm{f}_{1}=(0.3923) \cdot \mathrm{n}^{2}+(-1.2360) \cdot \mathrm{n}+(1.2451) \\
\mathrm{f}_{2}=(1.1455) \cdot \mathrm{n}^{2}+(-3.9609) \cdot \mathrm{n}+(4.5791) \\
\mathrm{f}_{3}=(2.4496) \cdot \mathrm{n}^{2}+(-9.5942) \cdot \mathrm{n}+(12.8985)\end{array}$ \\
\hline & 4 & $\begin{array}{l}\mathrm{f}_{1}=(0.7640) \cdot \mathrm{n}^{2}+(-2.2141) \cdot \mathrm{n}+(1.8635) \\
\mathrm{f}_{2}=(2.2459) \cdot \mathrm{n}^{2}+(-7.4501) \cdot \mathrm{n}+(8.3942) \\
\mathrm{f}_{3}=(4.8453) \cdot \mathrm{n}^{2}+(-18.6997) \cdot \mathrm{n}+(24.7352)\end{array}$ \\
\hline & 6 & $\begin{array}{l}f_{1}=(1.1719) \cdot n^{2}+(-3.6571) \cdot n+(3.6110) \\
f_{2}=(3.3340) \cdot n^{2}+(-10.8488) \cdot n+(11.9525) \\
f_{3}=(7.1318) \cdot n^{2}+(-26.8444) \cdot n+(34.5638)\end{array}$ \\
\hline & 8 & $\begin{array}{l}\mathrm{f}_{1}=(1.5569) \cdot \mathrm{n}^{2}+(-4.8252) \cdot \mathrm{n}+(4.7011) \\
\mathrm{f}_{2}=(4.3983) \cdot \mathrm{n}^{2}+(-14.0598) \cdot \mathrm{n}+(15.0946) \\
\mathrm{f}_{3}=(9.2603) \cdot \mathrm{n}^{2}+(-33.4961) \cdot \mathrm{n}+(41.0395)\end{array}$ \\
\hline & 10 & $\begin{array}{l}\mathrm{f}_{1}=(1.9354) \cdot \mathrm{n}^{2}+(-5.9327) \cdot \mathrm{n}+(5.6608) \\
\mathrm{f}_{2}=(5.3952) \cdot \mathrm{n}^{2}+(-16.5207) \cdot \mathrm{n}+(16.1158) \\
\mathrm{f}_{3}=(11.1720) \cdot \mathrm{n}^{2}+(-38.1918) \cdot \mathrm{n}+(43.2955)\end{array}$ \\
\hline & 12 & $\begin{array}{l}\mathrm{f}_{1}=(2.3051) \cdot \mathrm{n}^{2}+(-6.9570) \cdot \mathrm{n}+(6.4250) \\
\mathrm{f}_{2}=(6.3822) \cdot \mathrm{n}^{2}+(-19.1811) \cdot \mathrm{n}+(18.5515) \\
\mathrm{f}_{3}=(12.8055) \cdot \mathrm{n}^{2}+(-40.3035) \cdot \mathrm{n}+(39.8636)\end{array}$ \\
\hline & 14 & $\begin{array}{l}\mathrm{f}_{1}=(2.6749) \cdot \mathrm{n}^{2}+(-8.0125) \cdot \mathrm{n}+(7.2944) \\
\mathrm{f}_{2}=(7.2818) \cdot \mathrm{n}^{2}+(-20.9467) \cdot \mathrm{n}+(18.6298) \\
\mathrm{f}_{3}=(14.2468) \cdot \mathrm{n}^{2}+(-40.8632) \cdot \mathrm{n}+(33.3841)\end{array}$ \\
\hline & 16 & $\begin{array}{l}\mathrm{f}_{1}=(3.0252) \cdot \mathrm{n}^{2}+(-8.8545) \cdot \mathrm{n}+(7.6656) \\
\mathrm{f}_{2}=(8.0857) \cdot \mathrm{n}^{2}+(-21.7434) \cdot \mathrm{n}+(16.4122) \\
\mathrm{f}_{3}=(15.4318) \cdot \mathrm{n}^{2}+(-39.1261) \cdot \mathrm{n}+(21.8871)\end{array}$ \\
\hline
\end{tabular}

length will be varied, and a single formula giving the natural frequency that also considers the model plate width and length will be constructed.

\section{REFERENCES}

${ }^{1}$ Mróz, Z. and Rozvany, G. Optimal design of structures with variable support conditions, J. Optim. Theory Appl., 15 (1), 85-101, (1975). https://dx.doi.org/10.1007/BF00933023

2 Jang, G. W., Shim, H. S. and Kim, Y. Y. Optimization of support locations of beam and plate structures under selfweight by using a sprung structure model, J. Mech. Des., 131 (2), (2009). https://dx.doi.org/10.1115/1.3042154

${ }^{3}$ Sapountzakis, E. An improved model for the analysis of plates stiffened by parallel beams including creep and shrinkage effects: application to concrete or to composite steel-concrete structures, Int. J. Eng. Appl. (IREA), 6 (2), 57-70, (2018). https://dx.doi.org/10.15866/irea.v6i2.15377

${ }^{4}$ Kawano, A. and Morassi, A. Uniqueness in the determination of loads in multi-span beams and plates, Eur. J. Appl. Math., 30 (1), 176-195, (2019). https://dx.doi.org/10.1017/S0956792517000419

${ }^{5}$ He, B. and Feng, Y. Vibration theoretical analysis of elastically connected multiple beam system under the moving oscillator, Adv. Civ. Eng., 2019, 4950841, (2019). https://dx.doi.org/10.1155/2019/4950841 
6 Takabatake, H. and Nagareda, Y. A simplified analysis of elastic plates with edge beams, Comput. Struct., 70 (2), 129-139, (1999). https://dx.doi.org/10.1016/s00457949(98)00164-3

7 Sapountzakis, E. J. and Katsikadelis, J. T. Dynamic analysis of elastic plates reinforced with beams of doublysymmetrical cross section, Comput. Mech., 23 (5), 430439, (1999). https://dx.doi.org/10.1007/s004660050422

8 Seo, S. H., Hong, S. Y. and Kil, H. G. Power flow analysis of reinforced beam-plate coupled structures, J. Sound Vib., 259 (5), 1109-1129, (2003). https://dx.doi.org/10.1006/jsvi.2002.5118

9 Rook, T. E. and Singh, R. Structural intensity calculations for compliant plate-beam structures connected by bearings, J. Sound Vib., 211 (3), 365-387, (1998). https://dx.doi.org/10.1006/JSVI.1996.1314

10 Chiba, M. and Yoshida, I. Free vibration of a rectangular plate-beam coupled system, J. Sound Vib., 194 (1), 49-65, (1996). https://dx.doi.org/10.1006/jsvi.1996.0343

$11 \mathrm{Hu}, \mathrm{C}$. and Hartley, G. A. Elastic analysis of thin plates with beam supports, Eng. Anal. Bound. Elem., 13 (3), 229-238, (1994). https://dx.doi.org/10.1016/0955-7997(94)90049-3

12 Galbrun, L. Vibration transmission through plate/beam structures typical of lightweight buildings: applicability and limitations of fundamental theories, Appl. Acoust., 71 (7), 587-596, (2010). https://dx.doi.org/10.1016/j.apacoust.2010.01.009

13 Shu, C. and Du, H. Implementation of clamped and simply supported boundary conditions in the GDQ free vibration analysis of beams and plates, Int. J. Solids Struct., 34 (7), 819-835, (1997). https://dx.doi.org/10.1016/S00207683(96)00057-1

14 Mitra, A., Sahoo, P. and Saha, K. Nonlinear vibration analysis of simply supported stiffened plate by a variational method, Mech. Adv. Mater. Struct., 20 (5), 373-396, (2013). https://dx.doi.org/10.1080/15376494.2011.627640

15 Mackerle, J. Finite element vibration analysis of beams, plates and shells, Shock Vib., 6 (2), 97-109, (1999). https://dx.doi.org/10.1155/1999/692380

16 Sapountzakis, E. J. and Katsikadelis, J. T. Analysis of plates reinforced with beams, Comput. Mech., 26 (1), 66-74, (2000). https://dx.doi.org/10.1007/s004660000156
17 Aydoğdu, M. and Taşkın, V. Vibration analysis of simply supported functionally graded beams, In İnan E., and Kırış A., Eds. Vibration Problems ICOVP 2005 (pp. 57-62). Springer Netherlands, Dordrecht, (2007). https://dx.doi.org/10.1016/j.matdes.2006.02.007

18 Sinha, L., Mishra, S., Nayak, A. and Sahu, S. Free vibration characteristics of laminated composite stiffened plates: experimental and numerical investigation, Compos. Struct., 233, 111557, (2020). https://dx.doi.org/10.1016/j.compstruct.2019.111557

19 Mikkola, A. M. and Shabana, A. A. A non-incremental finite element procedure for the analysis of large deformation of plates and shells in mechanical system applications, Multibody Syst. Dyn., 9 (3), 283-309, (2003). https://dx.doi.org/10.1023/A:1022950912782

20 Sun, L. and Wei, X. A frequency domain formulation of the singular boundary method for dynamic analysis of thin elastic plate, Eng. Anal. Bound. Elem., 98, 77-87, (2019). https://dx.doi.org/10.1016/j.enganabound.2018.10.010

21 Kukreti, A. R. and Cheraghi, E. Analysis procedure for stiffened plate systems using an energy approach, Comput. Struct., 46 (4), 649-657, (1993). https://dx.doi.org/10.1016/0045-7949(93)90393-R

22 Sobhani, E., Arbabian, A., Civalek, Ö. The free vibration analysis of hybrid porous nanocomposite joined hemispherical-cylindrical-conical shells, Engineering with Computers, (2021). https://dx.doi.org/10.1007/s00366021-01453-0

23 Civalek, Ö. and Avcar, M. Free vibration and buckling analyses of CNT reinforced laminated non-rectangular plates by discrete singular convolution method, Engineering with Computers, (2020). https://dx.doi.org/10.1007/s00366020-01168-8

24 Hadji, L. and Avcar, M. Free vibration analysis of FG porous sandwich plates under various boundary conditions, Journal of Applied and Computational Mechanics, (2020). https://dx.doi.org/10.22055/JACM.2020.35328.2628

25 AlSaid-Alwan, H. H. S. and Avcar, M. Analytical solution of free vibration of FG beam utilizing different types of beam theories: A comparative study, Computers and Concrete, 26 (3), 285-92, (2020). https://dx.doi.org/10.12989/cac.2020.26.3.285

26 Zhang, J., Ullah, S., Gao, Y., Avcar, M. and Civalek, Ö. Analysis of orthotropic plates by the two-dimensional generalized FIT method, Computers and Concrete, 26 (5), 421427, (2020). https://dx.doi.org/10.12989/cac.2020.26.5.421 